\title{
Review of 13 fetal cases with hepatic veins opening variously into the inferior vena cava within the diaphragm
}

\author{
Emine Hilal Evcil, Mehmet Ali Malas, Kadir Desdicioğlu \\ Department of Anatomy, Faculty of Medicine, Siileyman Demirel University, Isparta, Turkey
}

\begin{abstract}
Objectives: We aimed to investigate the 13 fetal cases with hepatic veins opening variously into the inferior vena cava within the diaphragm.

Methods: The study was carried out on 13 human fetuses (seven males and six females) aged between 21-40 weeks of gestation. The diaphragm, foramina on the diaphragm, inferior vena cava and the hepatic veins were exposed by thoracoabdominal dissections. In 13 fetal materials, variations in the foramina of the hepatic veins into the inferior vena cava on the undersurface of the diaphragm were observed.

Results: In 13 fetal materials, the hepatic veins did not directly open into the inferior vena cava but formed accessory foramen/foramina on the undersurface of the diaphragm and joined the inferior vena cava within the diaphragm. Accompanying the caval opening, there were 1-3 accessory foramina on the inferior but not superior surface of the diaphragm in 13 cases. A single hepatic vein in nine cases, two hepatic veins in two cases and three hepatic veins in two cases were found to open into the inferior vena cava within the diaphragm.

Conclusion: Physicians and researchers should be aware of the fact that during the fetal period, hepatic veins can open into the inferior vena cava with different ways within the diaphragm. These variations need to be taken into consideration in evaluating the caval opening on the diaphragm during obstetric ultrasonography and surgical interventions in the prenatal period.
\end{abstract}

Key words: hepatic vein; caval opening; diaphragm; inferior vena cava; variation

Anatomy 2009; 3: 29-34, ㅇ 2009 TSACA

\section{Introduction}

Venous blood of the liver drains to the inferior vena cava (IVC) via the hepatic veins (HVs). ${ }^{1}$ Usually a total of three HVs leave the liver though numerical variations is not uncommon..$^{2-5}$ Sometimes there is a single right hepatic vein while left and intermediate hepatic veins join to form a common trunk. ${ }^{2,3}$ An accessory vein (accessory hepatic vein) accompanying the HVs has also been reported. ${ }^{2,4}$
Studies on the variations of the HVs, which normally drain to the IVC, reported that these veins can also open directly to the heart chambers. ${ }^{3,6-9}$ These variations in which the HVs drain directly to the heart rather than via the IVC usually occur when IVC is absent or continues with the azygos vein and these variants pass either through the caval opening (CO) or accessory foramina on the diaphragm. ${ }^{3,7,8}$ 
Knowledge of these variations is important in surgical interventions between the diaphragm and the liver and fetal obstetrics. A literature search did not show any publications on the presence of such variations on the diaphragm during the fetal period. In the present study, we reviewed 13 fetuses with HVs draining to the IVC within the diaphragm.

\section{Materials and Methods}

The study was carried out on 13 (7 males and 6 females) human fetuses aged between 21-40 weeks of gestation which were identified during the course of a doctoral study entitled "Development of the diaphragm during the fetal period". These cases were considered as variations and were not included in the thesis and presentation of these as a separate study was deemed more appropriate. Study materials were obtained from the Department of Anatomy of Süleyman Demirel University which were collected between 1996 and 2003 from Isparta Maternity and Children's Hospital by their families' consent. Ethics Committee of Faculty of Medicine of Süleyman Demirel University approved the study prior to the commencement.

Gestational ages of the fetuses were determined using crown-rump length (CRL), bi-parietal diameter (BPD), head circumference (HC), femur length (FL) and foot length (FtL). Once the gestational ages of the fetuses were determined, general external measurements were taken and the diaphragm and neighboring viscera were exposed by thoraco-abdominal dissection. Moreover, intra-thoracic and intra-abdominal viscera were excised to differentiate the boundaries of the superior and inferior surfaces of the diaphragm. Hence, the IVC, the HVs and the foramina on the diaphragm, namely $\mathrm{CO}$, aortic hiatus $(\mathrm{AH})$, and the esophageal hiatus $(\mathrm{EH})$ were exposed. The HVs were observed to join the IVC within the diaphragm after forming accessory foramina on the undersurface of the diaphragm. Mean diameters of the accessory foramina made by the HVs when they opened to the IVC and the CO using a digital caliper [Mean diameter was calculated using the formula: (transverse diameter + vertical diameter)/2].

\section{Results}

General external parameters of the fetuses (CRL, $\mathrm{HC}, \mathrm{BPD}, \mathrm{FL}$ and FtL) were measured and gestational ages of the fetuses were determined based on these measurements (Table 1).

The relationships between the diaphragm and the neighboring viscera were found to be normal when the diaphragm was exposed with thoraco-abdominal dissection. Moreover, there were no pathologies or anomalies regarding the viscera neighboring the superior or inferior surfaces of the diaphragm. We, then, examined the foramina on the diaphragm $(\mathrm{CO}, \mathrm{AH}, \mathrm{EH})$ and the relation between the diaphragm and IVC and HVs. The relationship between the $\mathrm{AH}, \mathrm{EH}$ and their contents were normal.

In 13 cases, IVC passed through the $\mathrm{CO}$ on the diaphragm and opened into the right atrium. We noted that the HVs from the liver penetrated the undersurface of the diaphragm at 1-3 accessory foramina around the $\mathrm{CO}$ and opened into the IVC within the diaphragm (Figures 1-3). Among the 13 cases, there was one accessory foramen (Type 1) in 9, two foramina (Type 2) in 2, and three foramina (Type 3) in 2 cases, accompanying the CO.

HVs passing through the accessory foramina (foramen venae hepaticae 'FVH') opened into the IVC within the diaphragm (Figures 1-3).

When we examined the localizations of the FVHs with respect to the $\mathrm{CO}$ on the undersurface of the diaphragm, FVH was on the right side of the $\mathrm{CO}$ in all of the Type 1 cases (posterior to the $\mathrm{CO}$ in six cases, anterior to $\mathrm{CO}$ in one case and at the same level in two cases). Among Type 2 cases, both FVHs were on the right side of the $\mathrm{CO}$ in one case (anterior and posterior to it) whereas the FVHs were posterior to the $\mathrm{CO}$, one on the right and one on the left side, in the second case. In one of the Type 3 cases, all FVHs were on the right side of the $\mathrm{CO}$ (one in the anterior, and two in the posterior) whereas two foramina were on the right and one opening was on the left side of the CO, all foramina being on the posterior aspect of the $\mathrm{CO}$, in the other case.

These were followed by measuring the mean diameters of the CO and FVHs accompanying the CO (Table 2). 


\section{Discussion}

HVs carry the venous blood of the liver and the venous blood that comes with the portal vein to the IVC. Usually numbering three (right, left and intermediate hepatic veins), HVs open into the IVC, which travels in the groove for vena cava on the posterior surface of the liver, beneath the diaphragm. ${ }^{1}$

Previous studies reported numerical variations of the HVs leaving the liver. ${ }^{2-5}$ Numerous studies reported that the right hepatic vein left the right hepatic lobe, ascended by itself to open into the IVC while the left and intermediate hepatic veins joined to form a single vein (a trunk), left the left hepatic lobe and opened into the IVC or directly into the right atrium. ${ }^{2,3}$ Further, in addition to the VHs, occurrence of an accessory vein (accessory hepatic vein) draining the venous blood of certain hepatic segments has also been reported. ${ }^{2,4}$ Sometimes these accessory hepatic veins or the right hepatic vein passes through the CO alongside the IVC and drain directly into the right atrium. ${ }^{6}$ In the absence of IVC or when it continues with the azygos vein, the VHs have to pass through the $\mathrm{CO}$ on the diaphragm to reach the right atrium. ${ }^{3,6,9}$

Reviewing the general characteristics of 13 (7 males, 6 females) fetuses with hepatic veins opening into the IVC above the diaphragm showed that gestational ages of the fetuses ranged between 21 to 40 weeks. To the best of our knowledge, there are no publications in the literature that investigated these variations in the fetal period. Therefore, cases presented in this study are the first cases defined in this period. There was no clustering with regard to the gestational ages of the fetuses; the age distribution was even between 21 and 40 weeks (Table 1). There was also no sex difference among cases (7 males and 6 females).

Previous studies on adults showed that HVs can pass the diaphragm through accessory openings rather than $\mathrm{CO}$ and reach the heart directly, without opening into the IVC. ${ }^{3,7,8}$ In these studies, it was shown that the abnormal left hepatic vein opened into the right atrium either independently or via the coronary sinus. This vein, which originates from the left hepatic lobe, penetrates

Table 1

General external parameters of 13 fetuses $(\mathrm{mm})$

\begin{tabular}{|c|c|c|c|c|c|c|c|}
\hline $\begin{array}{l}\text { Case } \\
\text { number }\end{array}$ & $\begin{array}{c}\text { Age* } \\
\text { (week) }\end{array}$ & Sex & $\begin{array}{c}\text { CRL } \\
\text { (Crown-rump } \\
\text { Length) }\end{array}$ & $\begin{array}{c}\text { HCB } \\
\text { (Head } \\
\text { circumferance) }\end{array}$ & $\begin{array}{c}\text { PD } \\
\text { (Bi-parietal } \\
\text { diamater) }\end{array}$ & $\begin{array}{c}\text { FL } \\
\text { (Femur length) }\end{array}$ & $\begin{array}{c}\text { FtL } \\
\text { (Foot length) }\end{array}$ \\
\hline \multicolumn{8}{|c|}{ Type 1 (n:9) } \\
\hline 1 & 22 & $\mathrm{~F}$ & 210 & 180 & 45 & 41 & 42 \\
\hline 2 & 26 & $M$ & 250 & 246 & 65 & 52 & 53 \\
\hline 3 & 27 & $M$ & 258 & 253 & 68 & 54 & 55 \\
\hline 4 & 31 & M & 290 & 284 & 75 & 65 & 67 \\
\hline 5 & 33 & $\mathrm{~F}$ & 310 & 304 & 82 & 69 & 71 \\
\hline 6 & 35 & M & 330 & 320 & 86 & 72 & 75 \\
\hline 7 & 39 & $\mathrm{~F}$ & 380 & 349 & 95 & 80 & 81 \\
\hline 8 & 40 & $\mathrm{~F}$ & 406 & 348 & 97 & 81 & 82 \\
\hline 9 & 40 & M & 410 & 350 & 99 & 82 & 82 \\
\hline \multicolumn{8}{|c|}{ Type 2 (n:2) } \\
\hline 10 & 21 & M & 180 & 182 & 49 & 37 & 38 \\
\hline 11 & 21 & M & 186 & 189 & 54 & 38 & 39 \\
\hline \multicolumn{8}{|c|}{ Type 3 (n:2) } \\
\hline 12 & 32 & $\mathrm{~F}$ & 300 & 290 & 80 & 66 & 67 \\
\hline 13 & 32 & $\mathrm{~F}$ & 300 & 296 & 83 & 67 & 69 \\
\hline
\end{tabular}

* Gestational age (week) 
the diaphragm on the left side of the CO and opens into the right atrium. ${ }^{7,8}$ In a study performed on adult cadavers, the authors found that the common vein formed by joining of the intermediate and left hepatic veins passed through an accessory opening on the diaphragm near the $\mathrm{CO}$ and drained into the right atrium in $84 \%$ of the cases. $^{3}$ The authors attributed the occurrence of this abnormal veins to left sinus horn and venous duct formation during the embryonic life. ${ }^{7,8}$ In short, VHs do not open directly into the IVC but pass through either the $\mathrm{CO}$ or an accessory opening on the diaphragm to reach the right atrium in adults. ${ }^{3,7,8}$
In the present study, the HVs entered the diaphragm through 1-3 accessory opening(s) on its inferior surface and opened into the IVC without passing to the upper surface of the diaphragm. The number of the accessory foramina of the HVs on the undersurface of the diaphragm was 1 in nine cases, 2 in two cases and 3 in two cases (Figures 1-3; Table 2). HVs leaving the liver may be in 1-3 in number and enter these accessory foramina on the undersurface of the diaphragm and there appears to be no studies in the literature regarding these foramina in fetal life. Therefore, we termed these accessory foramina through which HVs pass as FVH.
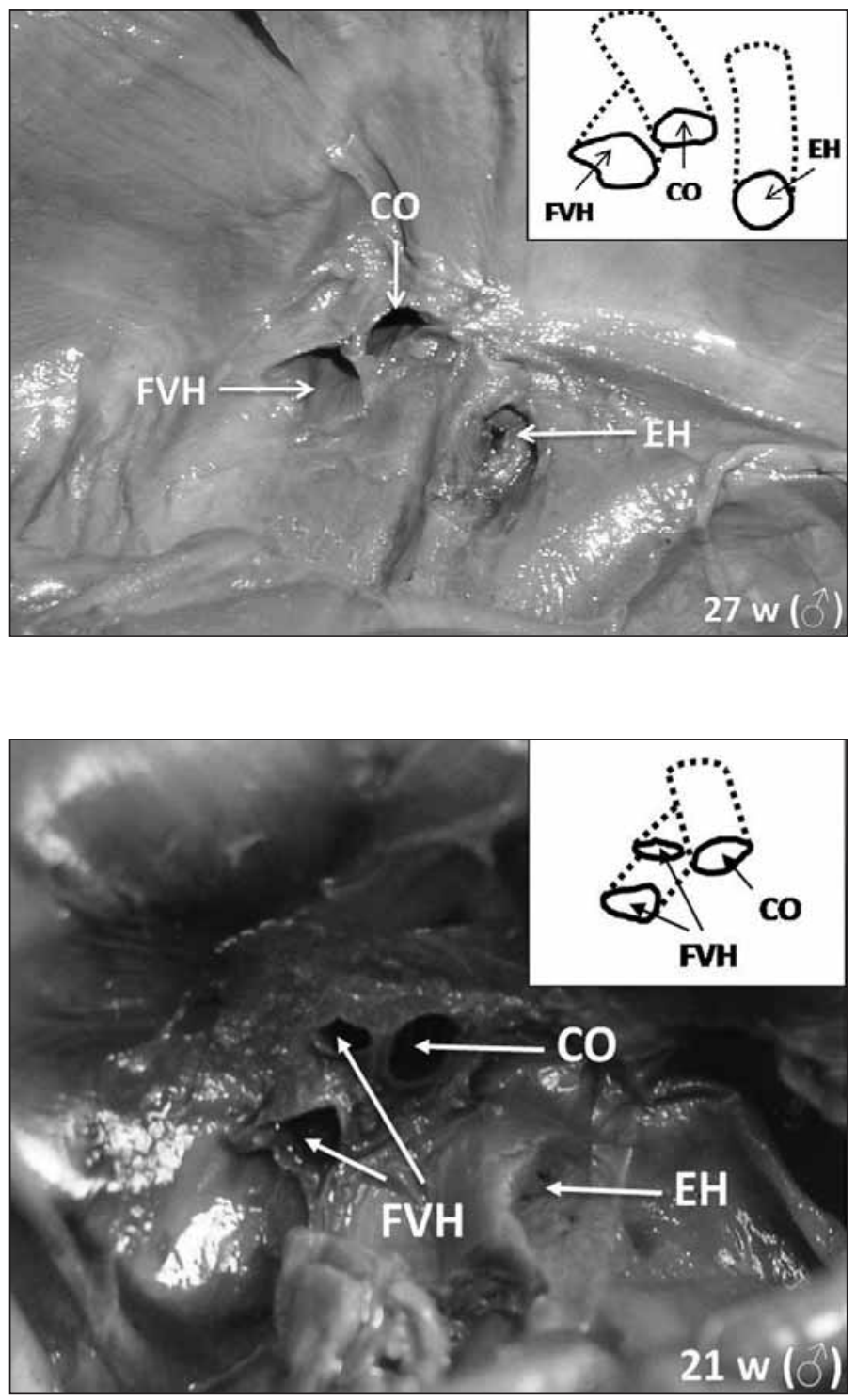

Figure 1. An accessory foramen accompanying the $\mathrm{CO}$ can be seen on the diaphragm of a 27-week-old male fetus (Type 1; CO: caval opening; FVH: foramen venae hepaticae; EH: esophageal hiatus).
Figure 2. Two accessory foramina accompanying the CO can be seen on the diaphragm of a 21-week-old male fetus (Type 2; CO: caval opening; FVH: foramen venae hepaticae; EH: esophageal hiatus). 
Table 2

Mean diameters of caval opening (CO) and foramen vena hepatica (FVH) observed on the diaphragm of 13 fetuses $(\mathrm{mm})$

\begin{tabular}{|c|c|c|c|c|c|c|}
\hline Case number & Age* (week) & Sex & $\mathrm{CO}$ & FVH 1 & FVH 2 & FVH 3 \\
\hline \multicolumn{7}{|l|}{ Type 3 (n:2) } \\
\hline 1 & 22 & $\mathrm{~F}$ & 1.75 & 1.50 & & \\
\hline 2 & 26 & M & 4. 00 & 5.00 & & \\
\hline 3 & 27 & M & 3.00 & 3.50 & & \\
\hline 4 & 31 & M & 5.00 & 5.00 & & \\
\hline 5 & 33 & $\mathrm{~F}$ & 6.00 & 4.50 & & \\
\hline 6 & 35 & M & 3.00 & 3.50 & & \\
\hline 7 & 39 & $\mathrm{~F}$ & 7.00 & 6.50 & & \\
\hline 8 & 40 & $\mathrm{~F}$ & 5.50 & 5.50 & & \\
\hline 9 & 40 & M & 4.50 & 3.00 & & \\
\hline \multicolumn{7}{|l|}{ Type 2 (n:2) } \\
\hline 10 & 21 & M & 2.00 & 2.00 & 1.00 & \\
\hline 11 & 21 & M & 2.50 & 1.00 & 1.00 & \\
\hline \multicolumn{7}{|l|}{ Type 3 (n:2) } \\
\hline 12 & 32 & $\mathrm{~F}$ & 3.50 & 3.50 & 3.50 & 3.50 \\
\hline 13 & 32 & $\mathrm{~F}$ & 3.50 & 1.00 & 2.00 & 4.00 \\
\hline
\end{tabular}

* Gestational age (week)

Moreover, these accessory foramina were present on the inferior but not superior surface of the diaphragm and HVs opened into the IVC within the diaphragm, i.e. they did not pass through the diaphragm. This finding, as opposed to previous studies, was not interpreted as a variation of the opening of HVs into the IVC (Figures 1-3).

Figure 3. Three accessory foramina accompanying the $\mathrm{CO}$ can be seen on the diaphragm of a 32-week-old female fetus (Type 3; CO: caval opening; FVH: foramen venae hepaticae).
Previous studies reported that the accessory foramina of the VHs on the diaphragm could be on either side of the CO. ${ }^{3,7}$ In the present study, we found them on the right side of the $\mathrm{CO}$ in all Type 1 cases (posterior to, at the same level with and anterior to the $\mathrm{CO}$ in 6, 2 and 1 case, respectively). One of the FVH in Types 2 and 3 were usually on the right side of the $\mathrm{CO}$ whereas the sec-

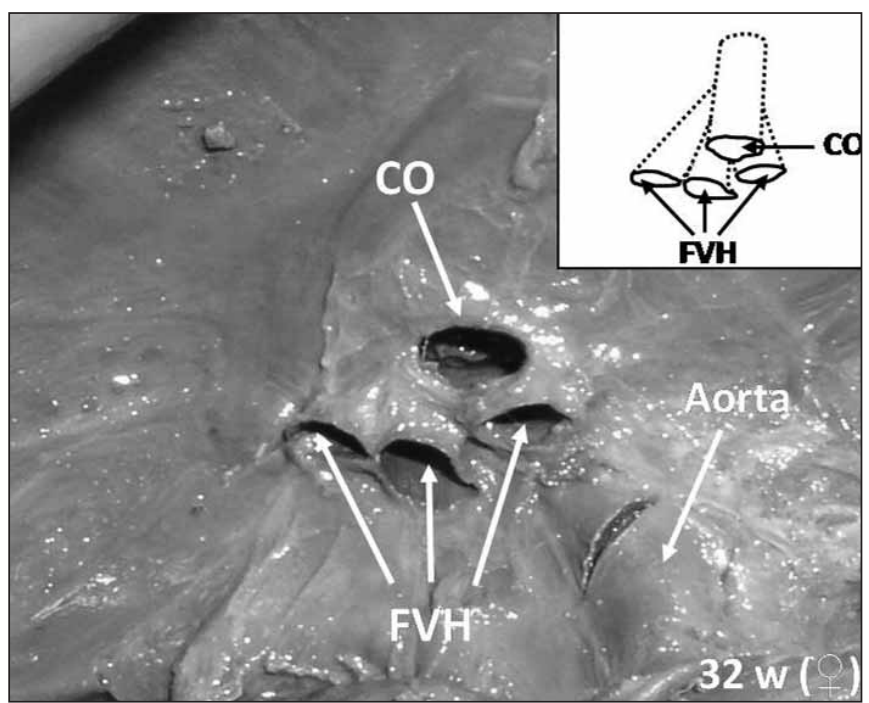


ond or third openings were located on the left side of the CO. These FVHs observed on the inferior surface of the diaphragm in fetuses aged 21-40 weeks of gestation were similar to those observed in adults reported in previous studies. Researchers have attributed variations in the number and openings of HVs to the left sinus horn and venous duct that the HVs develop from in the embryonic-fetal period. ${ }^{7,8} \mathrm{We}$ believe that these variations observed in our cases in the second half of the pregnancy can persist in adulthood. Further, uniqueness of the openings of the HVs, which enter the diaphragm on its inferior surface and around the CO but do not exit the superior surface, into the IVC within the diaphragm should be noted.

We also calculated the mean diameters of the CO and FVHs accompanying the CO (Table 2). An increase in the $\mathrm{CO}$ diameter with fetal age has been reported in previous studies. ${ }^{10}$ On the other hand, we did not find a linear increase in the diameters of CO and FVHs of 13 cases with fetal age (Table 2). We believe this finding may be related to the variability in the number of HVs and to HVs opening into the IVC within the diaphragm rather than joining the IVC beneath the diaphragm.

A thorough knowledge of hepatic angio-architecture is essential for the success and reliability of hepatic surgery. ${ }^{4,11}$ Moreover, a surgical intervention between the liver and the diaphragm requires the knowledge of the relationship between the IVC and the HVs and its common variations. It should also be noted that $\mathrm{HV}$ s that are observed beneath the diaphragm during the fetal life may open into the IVC with different ways above the diaphragm. We concluded physicians should be aware of such variations while assessing the $\mathrm{CO}$ on the diaphragm by obstetric ultrasound in prenatal period.

\section{References}

1. Borley NR. Hepatobiliary system. In: Standring S, ed. Gray's Anatomy. The Anatomical Basis of the Medicine and Clinical Practice. 39th ed. Edinburgh: Elsevier-Churchill Livingstone; 2005. p. 1213-26.

2. Bergman RA, Afifi AK, Miyauchi R. Hepatic veins. In: Illustrated Encyclopedia of Human Anatomic Variation: Opus II: Cardiovascular System: Veins: Abdomen. http://www.anatomyatlases.org/AnatomicVariants/Cardiovascular/Text/Veins/Hepatic.s html (8th of January, 2009).

3. Wind P, Douard R, Cugnenc PH, Chevallier JM. Anatomy of the common trunk of the middle and left hepatic veins: application to liver transplantation. Surg Radiol Anat 1999; 21: 17-21.

4. Buhe S, Miyaki T, Saito T, et al. A study of the accessory hepatic vein to segments VI and VII with a morphological reconsideration of the human liver. Surg Radiol Anat 2008; 30: 201-7.

5. Fan ST, Wong Y. Absent middle hepatic vein in a right liver graft donor. Hepatobiliary Pancreat Dis Int 2008; 7: 430-2.

6. Bergman RA, Afifi AK, Miyauchi R. Inferior vena cava. In: Illustrated Encyclopedia of Human Anatomic Variation: Opus II: Cardiovascular System: Veins: Abdomen. http://www.anatomyatlases.org/AnatomicVariants/Cardiovascular/Text/Veins/InferiorV enaCava.shtml (8th of January, 2009).

7. Azuma C, Tohno Y, Tohno S, Moriwake Y, Utsumi M, Yamada M. Persistent left hepatic venous connection with the right atrium and the ductus venosus. Anat Sci Int 2002; 77: 124-7.

8. Yoshinaga K, Kodama K. Persistence of the hepatic segment of the left inferior vena cava in man and its relation to the ductus venosus development. Acta Anat (Basel) 1997; 160: 132-8.

9. Stoller JK, Hoffman RM, WhiteRD, Mee RBB. Anomalous hepatic venous drainage into the left atrium: an unusual cause of hypoxemia. Respir Care 2003; 48: 58-62.

10. Malas MA, Evcil EH, Desdicioglu K. Size and location of the fetal diaphragm during the fetal period in human fetuses. Surg Radiol Anat 2007; 29: 155-64.

11. Sahani D, Mehta A, Blake M, Prasad S, Harris G, Saini S. Preoperative hepatic vascular evaluation with CT and MR angiography: implications for surgery. RadioGraphics 2004; 24: 1367-80.

Correspondence to: E. Hilal Evcil, MSC

Department of Anatomy, Faculty of Medicine,

Süleyman Demirel University

Isparta 32040 Turkey

Phone: +90 24621133 05-3303; Fax: +90 2462371165

e-mail: hilalevcil@hotmail.com

Conflict of interest statement: No conflicts declared. 